\title{
Sustainability Of Substantially Equal Periodic Payments In Early Retirement Under Section 72(t)
}

Carl M. Hubbard, Trinity University, USA

\begin{abstract}
Early distributions from tax-deferred retirement plans are allowed without penalty but must continue under for the longer of five years or until the retiree's age 591/2. Early distributions under IRS Section 72(t) potentially have life altering consequences and thus require analysis of sustainability distributions through the 72(t) period.
\end{abstract}

Keywords: Section 72(t), retirement income, substantially equal periodic payments, sustainability

\section{INTRODUCTION}<smiles>[C]1C=CCCC=C1</smiles>

ection 72(t) of the Internal Revenue Code of 1986 allows retirees to take early distributions from taxdeferred retirement plan without penalty. Penalty-free early distributions under 72(t) must be calculated using one of three formulas provided by the IRS and must continue for a minimum of five years or more. Because of the inflexible nature of 72(t) and the possibility of early depletion of retirement funds, the decision to take early distributions under 72(t) must be examined carefully and objectively. Attention should be focused on the expected impact of the calculated withdrawals and fees on the retirement portfolio through the minimum 72(t) period during which withdrawals are fixed. Since retirees expect to survive many years beyond the 72(t) period, this subject should be of concern to those who are considering financing early retirement with early distributions from tax-deferred retirement funds.

The importance of this subject is illustrated by a recent Associated Press report (Krisher, 2007) that 27,000 Ford Motor Company workers have left the company with buyout and early retirement offers, half of whom were not eligible for retirement. Early retirees who have tax-deferred retirement funds must make the decision of whether to begin distributions under $72(\mathrm{t})$ or wait until age $59 \frac{1}{2}$. Representatives of financial services companies who earn their living by winning new accounts may lack incentive or character to be candid with financially unsophisticated clients regarding sustainable withdrawal rates. A clever presentation of an amortization table that ostensibly shows the sustainability of 10 percent withdrawals convinces some to retire early and thereby give up their most valuable assets - their jobs. Although the literature on sustainable withdrawal rates clearly warns against high withdrawal rates, the average early retiree likely is not aware of those articles. Thus they are likely to be unaware of how rapidly fixed high withdrawal rates in sluggish or bear market conditions can deplete their life savings within the 72(t) period.

This article reviews Section 72(t) of the Internal Revenue Code as amended by Rev. Rul. 2002-62 and examines the sustainability of annual withdrawal rates that result from calculations of substantially equal periodic payments (SEPP) as described in Section 2 of Rev. Rul. 2002-62 (Internal Revenue Service, 2002). The analysis suggests that the combination of withdrawal rates and expense ratios that combined are above 5 percent are likely to deplete retirement portfolio balances to less than 90 percent of the original values by the end of seven years. In such cases post-72(t) retirement must be financed with less than 90 percent of the original retirement funds. While such an outcome may be acceptable to some who are considering early retirement, a quantitative analysis of withdrawal rates and expected portfolio values should be considered before initiating one of the two higher SEPP calculation methods that are described in Rev. Rul. 2002-62. The effects of other variables such as length of the 72(t) period, 
portfolio asset allocation between stocks and bonds, and investment management expenses on portfolio value are also illustrated in the analyses.

\section{SUBSTANTIALLY EQUAL PERIODIC PAYMENTS}

Section 72(t) allows early distributions from tax-deferred retirement plans provided the early distributions are in the form of substantially equal periodic payments, or SEPP, taken no less frequently than annually. According to Revenue Ruling 2002-62 there are three alternative methods of calculating SEPP from tax-deferred plans - the minimum distribution method, the fixed annuitization method, and the fixed amortization method. After early distributions are begun, the retiree is must continue his or her chosen SEPP distribution method for the longer of 5 years or to age $591 / 2$, the $72(\mathrm{t})$ period, with one exception. A retiree who initiates annuitized or amortized distributions and subsequently observes that his/her portfolio is depleting too rapidly may make a one-time change in distribution methods and that is to the minimum distribution method. Although the switch to minimum distributions slows the portfolio depletion, the minimum distribution method of calculating distributions must then be continued for the remaining life of the retiree. Thus the decision to annuitize or amortize a tax-deferred retirement portfolio under 72(t) when prevailing interest rates are high is one of the most important and potentially risky decisions an early retiree must make.

In the minimum distribution method distributions within a year are calculated initially and recalculated each subsequent year by dividing the remaining retirement portfolio balance by the remaining life expectancy as provided in tables published by the Internal Revenue Service (IRS). For example, if the initial retirement account balance is $\$ 500,000$ and the taxpayer/retiree's age is 55 , the remaining life expectancy in the IRS uniform life table is 41.6 years and the first year's distribution is $\$ 500,000 / 41.6$ or $\$ 12,019$. The following year's distribution is recalculated by dividing the remaining account balance by 40.7 , the uniform life expectancy at age 56 , and so forth to the end of the $72(\mathrm{t})$ period. The annual withdrawal rate that results from the minimum distribution method in this example ranges from 2.4 percent of the initial portfolio value in the age 55 example to 2.65 percent at age 59 .

Certainly the annual withdrawals that are calculated in the minimum distribution method should be sustainable and indeed should allow most portfolios in typical historical market conditions to grow over a five to ten year 72(t) period. However, early retirees, say at age 55 or so, have longer life expectancies than they would have at age 65, and are likely to have smaller accumulations of retirement funds than if they had worked an additional 10 years. Thus the modest distributions using the minimum distribution calculation method may not be sufficient to cover living costs and may not offer sufficient incentive for early retirement.

The related problems of sustainability of withdrawals and portfolio depletion arise when early retirees choose either the fixed annuitization method or the fixed amortization method of calculating SEPP when prevailing interest rates are high. The word "fixed" indicates equal amounts must be withdrawn during each year of the 72(t) period. In the fixed annuitization method annual distributions are calculated by dividing the retirement fund balance near the date of retirement by an annuity factor that is derived from a combination of the current federal mid-term rate as published by the IRS, or up to 120 percent of the mid-term rate and statistics from a mortality table that is provided by the IRS. Calculators, such as the one at http://www.finance.cch.com/, are available online for this otherwise tedious calculation. When interest rates are higher, the annuity values of SEPP are higher thus making early retirement distributions appear attractive and practical. The fixed amortization method calculates the annual distribution amount as simply the level annual amount that amortizes the retirement fund over the remaining life expectancy of the retiree. As in the annuitization method the annual distribution is directly related to the amount of funds to be amortized and prevailing interest rates and is inversely related to the number of years of life expectancy.

The following examples illustrate the fixed annuitization method and the fixed amortization method of calculating SEPP. As in the minimum distribution example above, assume a beginning account balance of $\$ 500,000$ at age 55 and a uniform life expectancy of 41.6 years. If 120 percent of the mid-term rate is 8.0 percent, the annual value of SEPP using the fixed annuitization method is $\$ 43,151$; the annual value of SEPP calculated from the fixed amortization method is $\$ 41,697$. The effective annual withdrawal rates of these two methods are 8.63 percent $(\$ 43,151 / \$ 500,000)$ and 8.34 percent $(\$ 41,697 / \$ 500,000)$ of the beginning portfolio balance before considering the 
annual expense ratio. When interest rates are lower, the SEPP values calculated by annuitization or amortization are correspondingly lower.

As indicated above, both the fixed annuitization and fixed amortization methods combined with higher interest rates yield higher SEPP values which make early retirement appear financially feasible. However, the high withdrawal rates associated with a period of high interest rates that is followed by lower-than-expected portfolio returns can result in an unanticipated rapid depletion of the retirement portfolio especially when combined with higher portfolio expense ratios. Nevertheless during the 72(t) period a retiree in that unfortunate situation has the choice of continuing depleting withdrawals from the portfolio, switching to the minimum distribution method for the remainder of his or her life, or paying a penalty on early distributions. This potential hazard of early retirement is the subject of the NASD Investor Alert of September 14, 2006 in which the NASD warns investors not to be taken in by financial representatives who attempt to justify high withdrawal rates with overly optimistic projections of stock market returns.

\section{SUSTAINABILITY OF SEPP WITHDRAWALS}

In order to examine the sustainability of relevant portfolio withdrawal rates over periods of years that are equivalent to 72(t) periods, portfolio values were calculated net of distributions and net of expenses at the end of 5 , 7, and 10 years of distributions. Each of the ending portfolio values reported in Tables 1, 2, and 3 is the average value of 1,000 simulated portfolios with beginning values of $\$ 1,000$. The portfolio values are calculated at the end of after of fixed withdrawals of 4 percent to 9 percent of $\$ 1,000$ and after deducting annual expense ratios of $1 / 2$ percent, 1 percent, and 2 percent of current portfolio values. The fixed withdrawals are distributed monthly and expenses are deducted quarterly in the simulations. The following equation illustrates the calculation of the value of a simulated portfolio at the end of a month.

$\mathrm{V}_{\mathrm{t}}=\mathrm{V}_{\mathrm{t}-1}\left(1+\mathrm{R}_{\mathrm{t}}\right)-\mathrm{W}$

in which $V_{t}$ is the end of month value of the portfolio after adding investments returns $\left(R_{t}\right)$ and after deducting the fixed withdrawal. At the end of every three months the portfolio management expense is calculated by multiplying the indicated expense ratio times $V_{t}$, and that amount is then deducted from the portfolio.

The expense ratios reflected in Tables 1,2, and 3 can be related to the different mutual fund companies or to different classes of mutual funds. Since the effects of front-end load fees are not included in the analyses, the beginning values of $\$ 1,000$ must be viewed as the initial investment amount prior to the first distribution and after deducting any brokerage or load fee.

All portfolio values are calculated using simulated monthly portfolio returns that in turn are derived from average monthly returns to the S\&P 500 and average monthly returns high-grade corporate bonds from January 1946 to December 2006 returns reported by Morningstar (2007) minus withdrawals and expenses. The average monthly S\&P 500 return for the 61-year sample period is 1.0 percent per month and average monthly returns to high-grade corporate bonds is 0.51 percent. Standard deviations of monthly returns are 4.11 percent for S\&P 500 returns and 2.22 percent for bond returns. Security returns are assumed to be log normally distributed in the simulation program. No adjustment for mean reversion or serial correlation of security returns was included in the simulations. Portfolio asset allocations range from 60 percent stocks and 40 percent bonds to 40 percent stocks and 60 percent bonds.

Table 1 reports the average values of the simulated portfolios at the end of years 5, 7, and 10 after withdrawals of 4 percent through 9 percent of the initial $\$ 1,000$ balance and after $1 / 2$ percent fees. The average ending portfolio values in Table 1 are related to SEPP calculations by way of the effective annual withdrawal rate of an annual distribution. In the examples above, the amortization calculation provided annual value of SEPP of $\$ 41,697$ from an initial balance of $\$ 500,000$, and the fixed withdrawal rate in that case would be about 8 percent. If the expense ratio of the mutual fund chosen by a hypothetical retiree were $1 / 2$ percent per annum, the early retiree with a portfolio of 60 percent stocks and 40 percent bonds could expect the portfolio to decline to about $\$ 881$ after 5 
years, $\$ 843$ after 7 years, and $\$ 792$ of the original balance after 10 years. A lower SEPP that is equivalent to a withdrawal rate of 6 percent is more likely to be sustainable even in the long run if a remainder of 90 percent of the original value is acceptable. In Table 1 average portfolios of at least 50 percent equity completed the 5 to 10 year periods net of 6 percent withdrawals and expenses with values of 90 percent or more of the original portfolio value. Distributions of 7 percent were sustainable under the 90 percent rule in portfolios of 60 percent stock and 40 percent bonds. The 5 percent withdrawal rate resulted in average portfolio values of $\$ 900$ in all years and with all three asset allocations. As in other similar studies lower allocations to common stocks lowers the average ending values of portfolios. For example 8 percent withdrawals from the 40 percent stock/60 percent bond portfolios rather dramatically depleted the average values of the bond-heavy portfolios to $\$ 813$ per $\$ 1,000$ of initial value after 5 years, $\$ 751$ after 7 years, and $\$ 665$ after 10 years.

Table 2 repeats the analysis reported in Table 1 except the annual expense ratio in Table 2 is doubled to 1 percent of the portfolio value annually. As expected the higher expense ratio lowered the average ending values of portfolios. Withdrawal rates of 7 percent or more reduced the 5 to 10 year portfolio values below $\$ 900$ of the initial $\$ 1,000$. In Table 2 withdrawals of 5 percent combined with the 1 percent expense ratio leaves 90 percent or more of the initial portfolio in all $72(\mathrm{t})$ periods. Thus the 0.5 percent increase in expense ratio reduces the sustainable withdrawal rate from 6 percent and occasionally 7 percent to about 5 percent when an ending portfolio value of $\$ 900$ per $\$ 1,000$ of initial value is deemed acceptable.

Table 3 reports further reductions of ending portfolio values when fixed distributions are combined with a 2 percent expense ratio which may be encountered in class B and C mutual fund shares as described in an NASD Investor Alert (2003). The statistics in Table 3 suggest that early retirees who withdraw 8 percent annually and pay a 2 percent expense ratio can expect 20 percent to 49 percent portfolio depletion depending on the length of the 72(t) period and the portfolio asset allocation. For shorter $72(\mathrm{t})$ periods and with at least 50 percent stock portfolios a withdrawal rate of 5 percent combined with the 2 percent annual expense ratio left about 88 to 95 percent of the original portfolio values. Overall, the sustainable withdrawal rate appears to shift down to the 4 percent to 5 percent range in Table 3 if 90 percent of the original portfolio value is the desired ending value.

\section{SUMMARY AND CONCLUSIONS}

Early distributions from tax-deferred retirement plans are allowed without penalty under Section 72(t) of the Internal Revenue Code but the retiree must take those distributions in the form of substantially equal periodic payments that are calculated using one of three methods described and illustrated in Rev. Rul. 2002-62. The calculated distributions must continue under $72(\mathrm{t})$ for the longer of five years or to age $59 \mathrm{1} / 2$. In order to avoid continued unexpected portfolio depletion, a retiree may make a one time change of the SEPP calculation to the minimum distribution method, but the minimum distribution calculations must continue for the remainder of the retiree's life. Thus, initiating early distribution of tax-deferred retirement funds under 72(t) is a serious and potentially life altering decision that should be undertaken only after thoughtful objective analysis of the sustainability of the effective annual withdrawal rate of the calculated SEPP distribution. Within the context of the asset allocations that are considered, the ending portfolio values in Tables 1, 2, and 3 suggest that withdrawal rates in excess of 5 percent combined with 1 percent or 2 percent expense ratios are likely to deplete the average retirement portfolio to 90 percent or less of its original value. Thus when interest rates rise, investors should be made aware of the likely depletion of their retirement portfolios over longer 72(t) periods when the early distribution is calculated by either the annuitization or amortization method.

Whether the reductions in portfolio values shown in the tables above are acceptable may be determined by other circumstances in the life of the retiree. For example, ill health may justify a more rapid draw down of a retirement account balance. Also, a retirement portfolio that is of high value relative to the retiree's basic budget requirements may allow the higher SEPP amounts and leave sufficient fund to support retirement after the $72(\mathrm{t})$ period has lapsed.

The desire to retire early is strong in many who have worked many years and expect little or no meaningful advancement. Some have worked long and hard in physically demanding occupations. Offers of early retirement 
with employer-enhanced retirement funds are very tempting. When considering such an opportunity, the expert advice of a financial planner who has no financial interest in any investments made by clients may prevent a serious mistake.

Naturally this article is not advice on income taxation or investments, but is intended to add analysis to the matters considered by financial planners and investors who are considering early retirement and early distributions under 72(t). The ending portfolio values in Tables 1, 2, and 3 are averages from Monte Carlo simulations that are calculated using historical security returns and therefore are not predications of future returns or investment results.

\section{AUTHOR INFORMATION}

Carl M. Hubbard is a Professor of Business Administration at Trinity University where he teaches financial management and investment analysis courses. In addition to service on various university committees, Dr. Hubbard serves on the Board of Directors of the South Texas Children's Home and on the Board of Trustees of McMurry University. He has authored and coauthored articles academic and professional journals including the Journal of Finance, Financial Management, Financial Services Review, Financial Counseling and Planning, the International Business and Economics Research Journal, the Journal of Retirement Planning, and the Journal of Financial Planning.

\section{REFERENCES}

1. Internal Revenue Service, Internal Revenue Bulletin No. 2002-42, October 21, 2002. http://www.irs.gov/pub/irs-irbs/irb02-42.pdf

2. Krisher, Tom. 2007. "27,000 workers have left Ford under buyout, early retirement," Associated Press News, June 15, 2007. http://www.post-gazette.com/pg/07166/794277-185.stm

3. Morningstar, Inc. 2007. Stocks, Bonds, Bills, and Inflation 2007 Yearbook. Chicago, Illinois.

4. NASD, NASD Investor Alert, "Don't Be Mislead By Early Retirement Investment Pitches That Promise Too Much," September 14, 2006. http://www.nasd.com/InvestorInformation/InvestorAlerts/

5. NASD, NASD Investor Alert, “Understanding Mutual fund Classes,” January 14, 2003. http://www.nasd.com/InvestorInformation/InvestorAlerts/ 
Table 1

Average Ending Portfolio Values After Withdrawals and Portfolio Management Fees of 1/2\% Per Annum

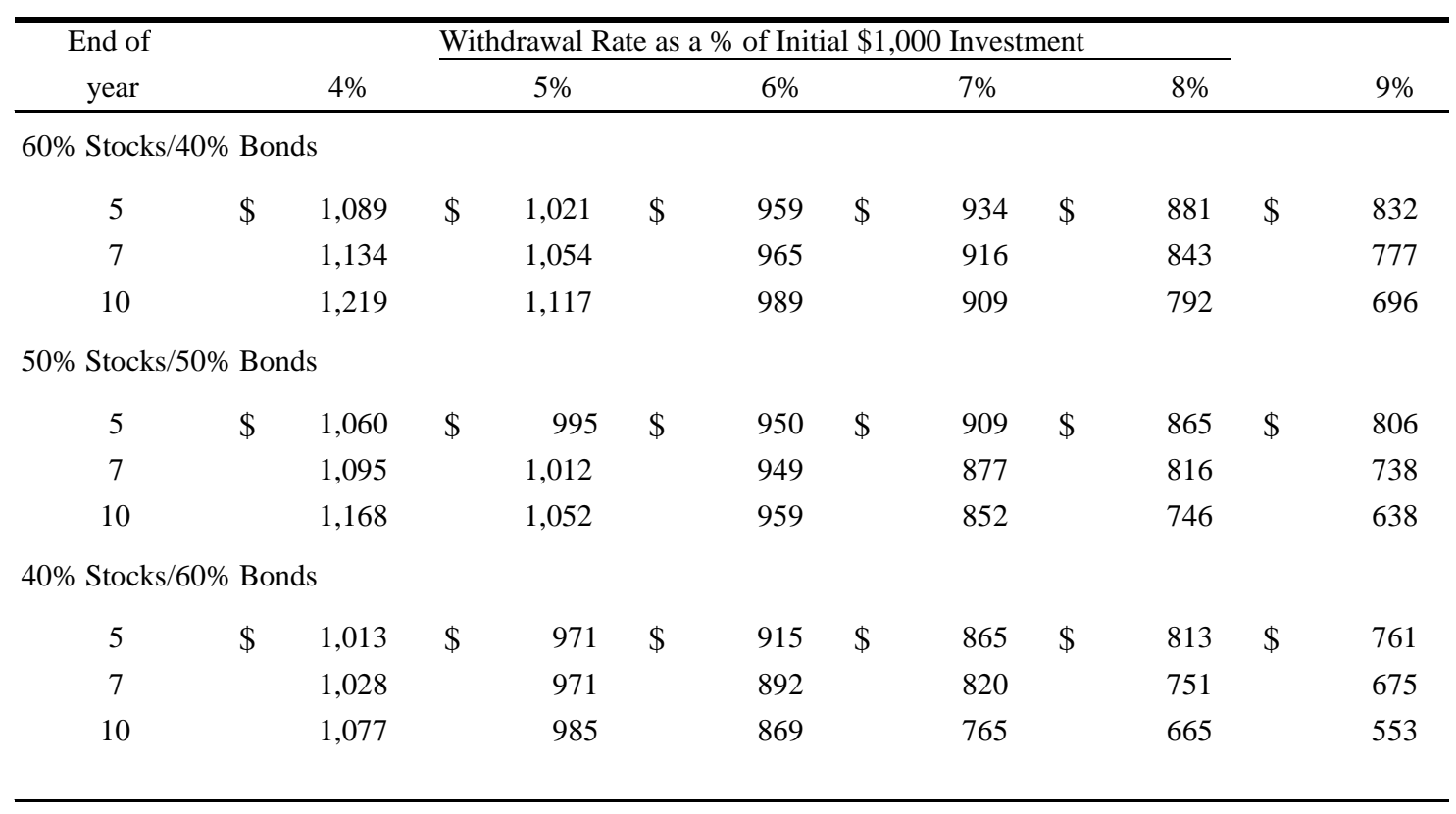

Note: Withdrawals are made at the end of each month and are calculated by multiplying the annual rates above divided by 12 times the initial value of $\$ 1,000$. Withdrawal rates do not include the expense ratio which is deducted quarterly as a percentage of current portfolio value. Year-end values above are averages of 1,000 portfolio values that are simulated for each year and each withdrawal rate using Monte Carlo simulation. The portfolios are rebalanced to the indicated allocations annually. Security returns are simulated from the average returns and standard deviations of returns to the S\&P 500 and high-grade corporate bonds. Both returns samples are monthly returns from January 1946 through December 2006 as reported in Stocks, Bonds, Bills, and Inflation - 2007 Yearbook by Morningstar (2007). 
Table 2

Average Ending Portfolio Values After Withdrawals and Portfolio Management Fees of 1\% Per Annum

\begin{tabular}{|c|c|c|c|c|c|c|c|c|c|c|c|c|}
\hline \multirow{2}{*}{$\begin{array}{c}\text { End of } \\
\text { year }\end{array}$} & & \multirow[b]{2}{*}{$4 \%$} & \multicolumn{8}{|c|}{ Withdrawal Rate as a \% of Initial \$1,000 Investment } & & \multirow[b]{2}{*}{$9 \%$} \\
\hline & & & & $5 \%$ & & $6 \%$ & & $7 \%$ & & $8 \%$ & & \\
\hline \multicolumn{13}{|c|}{$60 \%$ Stocks $/ 40 \%$ Bonds } \\
\hline 5 & $\$$ & 1,048 & $\$$ & 1,007 & $\$$ & 915 & $\$$ & 879 & $\$$ & 854 & $\$$ & 801 \\
\hline 7 & & 1,089 & & 1,017 & & 899 & & 851 & & 803 & & 730 \\
\hline 10 & & 1,147 & & 1,044 & & 884 & & 819 & & 741 & & 627 \\
\hline \multicolumn{13}{|c|}{$50 \%$ Stocks $/ 50 \%$ Bonds } \\
\hline 5 & $\$$ & 1,028 & $\$$ & 979 & $\$$ & 915 & $\$$ & 871 & $\$$ & 830 & $\$$ & 787 \\
\hline 7 & & 1,054 & & 980 & & 899 & & 836 & & 767 & & 706 \\
\hline 10 & & 1,098 & & 997 & & 884 & & 792 & & 689 & & 587 \\
\hline \multicolumn{13}{|c|}{$40 \%$ Stocks $/ 60 \%$ Bonds } \\
\hline 5 & $\$$ & 984 & $\$$ & 942 & $\$$ & 887 & $\$$ & 838 & $\$$ & 787 & $\$$ & 735 \\
\hline 7 & & 986 & & 931 & & 853 & & 783 & & 715 & & 640 \\
\hline 10 & & 1,014 & & 925 & & 812 & & 711 & & 614 & & 505 \\
\hline
\end{tabular}

Note: Withdrawals are made at the end of each month and are calculated by multiplying the annual rates above divided by 12 times the initial value of $\$ 1,000$. Withdrawal rates do not include the expense ratio which is deducted quarterly as a percentage of current portfolio value. Year-end values above are averages of 1,000 portfolio values that are simulated for each year and each withdrawal rate using Monte Carlo simulation. The portfolios are rebalanced to the indicated allocations annually. Security returns are simulated from the average returns and standard deviations of returns to the S\&P 500 and high-grade corporate bonds. Both returns samples are monthly returns from January 1946 through December 2006 as reported in Stocks, Bonds, Bills, and Inflation - 2007 Yearbook by Morningstar (2007). 
Table 3

Average Ending Portfolio Values After Withdrawals and Portfolio Management Fees of 2\% Per Annum

\begin{tabular}{|c|c|c|c|c|c|c|c|c|c|c|c|c|}
\hline \multirow{2}{*}{$\begin{array}{c}\text { End of } \\
\text { year }\end{array}$} & & \multirow[b]{2}{*}{$\%$} & \multicolumn{8}{|c|}{ Withdrawal Rate as a \% of Initial \$1,000 Investment } & & \multirow[b]{2}{*}{$\%$} \\
\hline & & & \multicolumn{2}{|r|}{$5 \%$} & \multicolumn{2}{|r|}{$6 \%$} & \multicolumn{2}{|r|}{$7 \%$} & \multicolumn{2}{|r|}{$8 \%$} & & \\
\hline \multicolumn{13}{|c|}{$60 \%$ Stocks $/ 40 \%$ Bonds } \\
\hline 5 & $\$$ & 999 & $\$$ & 947 & $\$$ & 903 & $\$$ & 849 & $\$$ & 796 & $\$$ & 766 \\
\hline 7 & & 1,009 & & 939 & & 877 & & 798 & & 729 & & 674 \\
\hline 10 & & 1,025 & & 932 & & 848 & & 734 & & 638 & & 556 \\
\hline \multicolumn{13}{|c|}{$50 \%$ Stocks $/ 50 \%$ Bonds } \\
\hline 5 & $\$$ & 967 & $\$$ & 914 & $\$$ & 869 & $\$$ & 822 & $\$$ & 772 & $\$$ & 714 \\
\hline 7 & & 968 & & 900 & & 826 & & 758 & & 692 & & 613 \\
\hline 10 & & 967 & & 881 & & 770 & & 674 & & 581 & & 467 \\
\hline \multicolumn{13}{|c|}{$40 \%$ Stocks $/ 60 \%$ Bonds } \\
\hline 5 & $\$$ & 936 & $\$$ & 879 & $\$$ & 826 & $\$$ & 794 & $\$$ & 740 & $\$$ & 690 \\
\hline 7 & & 920 & & 848 & & 772 & & 720 & & 644 & & 583 \\
\hline 10 & & 901 & & 798 & & 701 & & 616 & & 513 & & 430 \\
\hline
\end{tabular}

Note: Withdrawals are made at the end of each month and are calculated by multiplying the annual rates above divided by 12 times the initial value of $\$ 1,000$. Withdrawal rates do not include the expense ratio which is deducted quarterly as a percentage of current portfolio value. Year-end values above are averages of 1,000 portfolio values that are simulated for each year and each withdrawal rate using Monte Carlo simulation. The portfolios are rebalanced to the indicated allocations annually. Security returns are simulated from the average returns and standard deviations of returns to the S\&P 500 and high-grade corporate bonds. Both returns samples are monthly returns from January 1946 through December 2006 as reported in Stocks, Bonds, Bills, and Inflation - 2007 Yearbook by Morningstar (2007). 